\title{
CASE STUDY ON LUDOTHERAPY AND AROMATHERAPY IN SUPPORT OF TREATMENT IN PSYCHIATRIC PATIENTS
}

\author{
Maribel Gonzalez Carreon, Juan Manuel Sánchez-Soto², Cristina Juárez Landin², \\ Monica Celis Guzman ${ }^{3}$ \\ 1. PLEN del Centro UAEM Universitario Valle de Chalco \\ 2. Profesores de Tiempo Completo del Centro UAEM Universitario Valle de Chalco \\ 3. Profesores de Medio Tiempo del Centro UAEM Universitario Valle de Chalco
}

\begin{abstract}
Maribel Gonzalez Carreon, Juan Manuel Sánchez-Soto, Cristina Juárez Landin, Monica Celis Guzman (2022) Case Study on Ludotherapy and Aromatherapy in Support of Treatment in Psychiatric Patients, European Journal of Biology and Medical Science Research, Vol.10, No.1, pp.15-25
\end{abstract}

\begin{abstract}
The present research was carried out at the Samuel Ramírez Moreno psychiatric hospital, which aimed to describe the importance of recreational activities and aromatherapy for the treatment of psychiatric patients, the longitudinal qualitative study method a qualitative longitudinal cut study, involving $75 \%$ of patients with mental health. It is important to improve the quality of life of the patient, the activities aimed at stimulating their functionability, as well as to reduce the violence and stress that users constantly present during their hospital stay. The results showed that the recreational activities and aromatherapy produce cognitive stimulation, which is a set of pathways, forms, methods, and techniques that are effective in the functioning of capacities such as memory, language, and reasoning these functions are important to maintain intellectual skills in order to restore autonomy to the user. Its main benefits are physical and physiological: Expanding your body expression, stimulating concentration and mental agility, improving balance, increasing blood circulation This helps to release serotonin and endorphins. Recreational activities and aromatherapy are of utmost importance in the elderly, mainly in users with mental disorders so games are learning tools and cognitive activity as they stimulate the mind by forcing it to think and activate different skills in their daily life. Aromatherapy improves mood for relaxation, in situations of stress or anxiety has a soothing effect that facilitates relaxation and mental peace because essential oils can serve the balance between the right and left hemispheres.
\end{abstract}

KEY WORDS: psychiatric diseases, aromatics, Ludoterapia.

\section{INTRODUCTION}

This alteration is a manifestation primarily of reasoning, behavior and the loss of reality and of adapting to the conditions of life that generate social isolation a disorder of basic daily activities and problems to adapt to the environment. Most of these mental disorders are observable by the people around them, including the main physical symptoms are: Sleep disorders, sadness, fear and anxiety, difficulty thinking clearly, abnormal beliefs, memory disturbances, aggressive behavior due to visual or auditory disturbances. It is of the utmost importance to mention that these mental disorders are classified and arise most 
of them due to biological, genetic, neurological, environmental or psychological factors that have an impact on the affective and cognitive procedures of development which causes difficulties in reasoning, Alterations of thought and loss of reality (Falcó, 2015). The classification of mental disorders are: schizotypic symptomatic and organic, neurotic, behavioral and personality, behavior in childhood and adolescence, disorders due to consumption of psychotropic, mood or affective, mental disorders produced by physiological dysfunctions and mental retardation. From which derive disorders with high incidence in Mexico, $17 \%$ of people have at least one mental disorder, and one in four will suffer at least once in their lives. The people affected are currently the elderly and families in situations of violence (Rodríguez, 2008).

Delirium according to DSM-V, is defined as an alteration of consciousness and change in cognition that develops over a period of time, for its diagnosis the following criteria are required, alteration of consciousness difficulty in directing attention, change in cognitive functions. Delirium symptoms are common in the elderly and even more so in hospitalized patients, which is associated with an extended hospital stay (American Psychiatric Association, 2014).

Schizophrenia is a set of psychotic disorders, characterized by the presence of positive and negative psychotic symptoms. Its manifestations consist of a mixture of characteristic signs and symptoms. Symptoms affect multiple psychological processes, such as perception, hallucinations, ideation, reality check, delusions, catatonia behavior, concentration disorganization, motivation, and judgment (Clinical Practice Guide on Schizophrenia, 2009).

Metal delay is the difficulty of learning and the limitations in the activities of daily life. The author Alonso states that mental retardation manifests before the age of 18, which is when any individual is able to attribute to society and assumes adult roles. For a timely diagnosis it is basic to take the person's adaptive skills such as: Spoken word communication, writing, and language. Self-care, hygiene and physical appearance. Household skills and social skills. These should be evaluated and evaluated by specialist staff based on patient information obtained by different means such as interviews, direct observation, standardized teas duly adapted to each user (Alonso, 2006).

Epilepsy is one of the most common disorders within psychiatric hospitals that represents mainly cognitive problems that are derived from it and is a problem that requires a thorough clinical study. It is a chronic condition characterized by the presence of seizures or not, which are caused by an excessive discharge of brain neurones, associated with the various clinical and paraclinic manifestations (Duarte, 2004).

It is therefore of the utmost importance that the nurse in the area of psychiatry can offer treatments that favor and protect the health and well-being of each user, since the main objective of psychiatric hospitals is to enhance the skills and skills necessary for the user to learn to live within the hospital unit with his mental disorder by offering various 
treatments not only to resort to psychopharmaceuticals seek help with support of alternative therapy (Martinez, 2018).

Alternative therapies are healing resources based on practice, theories, beliefs, and experiences of the various cultures that are used in the maintenance of physical and mental health. It brings many health benefits: It reduces stress and anxiety levels, promotes the immune system to function properly, reduces stress and anxiety, decreases pain levels, and improves blood circulation.

Therefore, alternative therapy must be applied by the multidisciplinary staff of the hospital, covering various activities in which natural resources such as water, land, plants, exercise, the patient's own mind and energy are used. Some of the alternative therapies are, music therapy, aromatherapy, dance therapy, massage, reiki (Suarez, 2010).

These practices generate great impact on society because of their effectiveness not only pathological but also at the psychological level, taking into account the above points it is of the utmost importance that nursing knows and applies the therapies especially in vulnerable groups such as older adults with mental disorders, Nightingale tells us that it is essential that patient care be used methods that favor early recovery through modifications of the environment, always focusing on the humanitarian to compassionate skills, conscious that help patients to achieve a good physical and mental being.

One of these alternative therapies that offers great benefits to patients with mental disorders is aromatherapy which is considered as a therapeutic method that uses essences and oils that produce aromas to help users with their sufferings, achieving meditation and inner harmony (Palomo,2005).

Aromatherapy is considered an alternative therapy because it mainly helps in physical, mental, and emotional disorders. Since the brain registers twice as fast the aroma as the pain so inhaling different aromas are able to change the emotions.Due to the permeability of the oils and their high ipopilicity penetrate the skin and mucous membranes, therefore it can be applied by dermal or respiratory route, therefore through the olfactory organ the macroparticles come into contact with the central nervous system if the olfactory stimuli reach the deeper parts of the brain, the aroma passes through numerous nerve fibers and reaches the hypothalamus and thalamus that is the most important center of sensory stimuli. These glands are the set of the limbic system where emotional behavior, impulses, functioning for learning and memorization capacity are coordinated (Saz, 2010).

Aromatherapy currently seeks an anxiolytic effect in certain essences such as lavender, rose, lemon and mint have an effect, equilibrate, purifying, harmonizing and sedative improving the mood, other studies emphasize that these essential oils act on dopamine that helps generate an anxiolytic effect so that the essential oils already mentioned can be used in the different psychiatric disorders besides that their application can be through the following method: 
Inhalation: A very easy method as essential oils are applied directly or indirectly, by inhaling the oils, drops may be placed on a tissue and the patient breathes it gently or places essential oils on the skin or as a steam treatment.

Massage: Applied directly to skin, arms, back with circular massages. Aromatic Bath: A bath with warm water containing essential oils has a relaxing effect. Internal use: Some essential oils can be consumed in the form of infusions for the treatment of certain symptoms (Damian, 2013).

Another therapy used in psychiatric patients is Ludotherapy which is defined as a means of communication and expression through play dealing with major emotional problems. In the therapy we work a series of skills with the users who are able to enjoy the game, they immediately demonstrate happiness, joy, communication and companionship (Gaspar, 2018).

The author Pedro Gaspar mentions that the participation in the game is of the highest that in any other therapy and concentration, as well as the attention, getting many users to put interest that at other times would not put. Examples of some recreational therapies that can be performed with users are described below: Recreational therapy, sport, art, music therapy, group therapy and board games (Naples, 2017).

Recreational activities play a very important role in users' lives and can influence physical, mental, cognitive, and improve behavior for users who are aggressive with nurses and their own peers. improve the skills of everyday life.Playful skills are supportive networks with their unit partners and nursing staff, strengthens the social bond in their hospital life, respecting rules of coexistence with activities that can be very basic and simple, but that over time have a great cognitive impact.

Training in social skills with the psychiatric patient has become a common element within a large number of rehabilitation programs, and this seems to be justified for a number of empirically documented reasons (Almir del Prette, 2002). It is therefore essential that basic tools for the development of the skills of the user's life be put in place in this vulnerable population.

Endorphins are produced by our body producing joy and happiness, decreasing physical pain, improving emotional state, rest and sleep. Serotonin regulates mood, reduces stress, increases peace of mind by avoiding anxiety and aggressive or violent behavior. Oxytocin is a neurotransmitter that is associated with love, produces greater confidence and affection. Therefore, the development of this project is important as they are a great option, providing pleasant benefits of comfort that benefits in emotions, skills, group adaptation and personal security (Casanova, 2019).

Being able to control anxiety, aggression, and self-aggression that are one of the main problems in hospital stay due to the time that many of the users take. The importance of research lies mainly in alternative medicine specifically aromatherapy and Ludotherapy, 
as they can be applied quickly, are quite economical options and guarantee an effective and safe treatment. Patients are the direct beneficiaries by improving mental health. The following work will analyze behavioral changes in support of treatment in psychiatric patients using Ludotherapy and aromatherapy as an alternative therapy.

The greater our social skills and the greater the consistency of our behaviors with what we think and feel, and with the values we advocate, the better the external assessment we will receive regarding our social competence (Almir del Prette, 2002).

\section{METHODOLOGY}

The present research is a longitudinal qualitative study, the study was carried out in the long-stay psychiatric hospital, with a total of 20 users and the participation of 15 users was achieved, due to the mental disorders they suffer from. Where you analyze the behavior and behavior of users of the psychiatric hospital, in which their behavior is established, before and after the above-mentioned alternative therapies, with which they worked and analyzed day by day their own behavior and toward their peers. A log of work was carried out to carry out behavioral and behavioral changes in the evolutionary process of patients with aromatherapy and ludotherapy.The study was carried out with the principles of respect and equity for the rights of users and the non-violence of their integrity, due to the vulnerability that users present.

\section{RESULTS}

In the psychiatric hospital in the Long Stay Therapeutic Unit, with 20 users where the main diagnoses are Profound mental retardation, moderate mental retardation, epilepsy, behavioral problems, self-aggression and hetero aggression. Most of the patients were found in a street situation and reported to the authorities because of the aggression they presented to the people who were traveling and these were transfers to different psychiatric hospitals. other users had been in hospital facilities for their entire life since they were children and at the age of majority they were admitted to hospitalEspecially 5 patients who will name Juan Carlos, Aron, Napoleon, José Luis and Margarito, who presented aggression behaviors and it was very difficult to work with them and integrate them into the activities that were carried out in daily life within the psychiatric hospital. Juan Carlos A mutista user who continually suffered from self-aggression problems The user most of the days presented crying without any control, sadness, anxiety and aggression mainly in the head whipping on the limbs of the bars of the unit presenting crying and desperate cries for hours. A user isolated from other colleagues because the crowds of people caused him crying and stress, every day the user kept in his hands two plastic tubes because they were the ones that gave him a little security to not selfattack,there were occasions that the nursing staff he intervened verbally, with psychopharmaceuticals and restraint where the user finally sought to damage his lower and upper extremities with the friction that he caused, so it was extremely important to intervene with the user with different alternatives. 
Aron One of the users of aggressive robust complexion with staff and their colleagues, nurses report that the time it has taken in the psychiatric hospital has presented problems of self-aggression for no reason. I was able to observe his behavior and fixation with some of his companions who were wandering around the unit and for no reason were pushed or beaten by Aron, unfortunately in a psychiatric hospital you should always be alert and in the first months Aron had fixation against me, on many occasions i tried to push myself and flaunt my wrists so it was difficult for me to work in the unit and so it was necessary to work with him and observe his behavior very closely and also to know what made him have fixation with certain patients and nurses.

Napoleon was one of the users who apparently was very quiet and liked to participate in the daily activities that were carried out within the unit. A user who constantly changed his mood and feelings, in the slightest carelessness the user was only hitting his head on walls and windows of the window so it was important to keep his attention in certain activities to avoid his aggression.

José Luis A wheelchair user with whom I had the first nurse patient contact and since I met him I was able to perceive his rude and pessimistic attitude to any situation since he addressed any colleague or nurse with bad words and he beat blows everywhere, it was excellent food if not to his liking and could be out of eating so it was very difficult to integrate with colleagues and do activities together.

Margarito A time-active, unparticipatory user was aggressive with his peers to remove their belongings mainly if it was food, the user was heading with his peers and in a sudden manner removed the belongings or foods he chose. sometimes he screamed and tried to beat the staff.

Once patients were identified within a month, they were integrated into recreational activities and alternative therapies that favor the lives of psychiatric users, their integration was difficult because at first the patients mentioned did not allow them to be so close to them, so it became difficult to work with them. over the days, users watched the participation of other colleagues and gradually integrated. With Juan Carlos it was different because we headed to his bed and carried out a series of activities that are mentioned below recreational activities: therapeutic walk, physical activation, dancing with users, dominoes game, memorama game, motor skill toys, body therapy, painting, coloring and drawing, decorating the unit, break the piñata and karaoke.

Most users were involved in recreational activities and aromatherapy so it was easy to integrate and great changes were observed in each user since most of them followed basic orders of daily life so their participation in the recreational activities were enjoyable and they enjoyed the different activities that the users carried out day by day.

In the second month, 10 patients were integrated into the recreational activities and aromatherapy, the users who were the most aggressive and self-agreddared were integrated in the third month due to the mistrust and fear they presented. Because he was 
a new member of the unit, the users mentioned above were suspicious, but looking at the integration of the other colleagues, they were gradually interested mainly in aromatherapy, which is to apply small drops of lavender oil to wrists and ear lobe later there was incense of smells and relaxing music and for the best comfort of the user the mattress of the camels were placed on the floor to be able to have better contact with the users.

The daily recreational activities were carried out alternating each one, where 15 users were involved. The therapeutic walk was carried out daily at 5 in the afternoon with a duration of one hour in the company of the interns with music of their liking, who enjoyed quite leaving the unit, the users followed the orders and never showed any percance. The games that were played with the users were lottery, memorama, jenga, coloring and drawing the activities were carried out within the unit with a duration of one hour where his faction showed his joy and the fun that they presented when carrying out the activities mentioned above. The change in the 5 users mentioned above was evident. Juan Carlos on aromatherapy remained calm in his bed for the rest of the afternoon, observed more participative diminished his anxiety and fear of being with his companions, when music therapy was performed, the user was able to listen and integrate with it without having to go through it, he began to wander within the unit and to perform basic activities such as going to the bathroom for it, the changes in Juan Carlos were evident mainly in his face showing joy and tranquility, due to the constancy with which the activities already mentioned were carried out.

Aron greatly diminished his aggression with colleagues and with me, so he integrated himself into all the activities carried out, was participative, cooperative, his attitude was different at the end of each activity. Napoleon performed most of the activities, showing tranquility, emotion when performing the recreational activities mainly in the games and when singing or dancing, so the user no longer showed sadness or adinamia.

José Luis the most angry and rude user of the unit became a completely different user showing different attitudes at lunchtime, became kinder to the staff and his colleagues showed a face full of joy, emotion and when performing the aromatherapy he enjoyed it quite a lot most of the times the user fell asleep showing tranquility during the afternoon. Another of the activities I enjoyed to the fullest was listening to music, singing and dancing.

Margarito saw changes that slowed her aggressive and disturbing behavior toward her peers primarily in stripping her colleagues of their belongings. It was achieved to incorporate users in more complex activities within the unit in activities that were carried out each year as was Day of Death.

The users participated in decorating the unit and the emotion they presented was evident. The users were registered to the contest that took place every year inside the hospital where most of the users participated, their faces were painted and disguised a user who won the $3^{\circ}$ place and shared his prize with the other colleagues. 
In December the unit was embellished with lights, frost, spheres and a tree, the users were very happy when entering the unit especially Juan Carlos was one of the users who enjoyed the colors and the lights. so i decided to focus mainly on the area of her bedroom where she was watching and wandering around. They also made convivios with all the users, where they broke piñatas, sang, listened to music and danced, the users showed an integration and participation that they enjoyed all the time.

Psychiatric users are vulnerable, isolated, sad people who carry with themselves a rather difficult emotional burden because of the different circumstances of their lives they suffered, most of them abandoned, abused and abusedSo it is extremely important to focus on users, since psychiatry is not just a diagnosis and treatment. it is working day by day without forgetting the humanitarian side and above all being empathic and aware that the life that users carry is difficult and hard, that most of them carry a whole life enclosed in four walls, that their life is not beyond the dining room, corridors and a garden.

So you decide to make an emphasis on the users, leave their life so routine and give them a little joy, tranquility, fun, emotion and laughter with the playful activities that focus on a series of games and activities that certainly enjoyed enough and had an impact on their emotional state as well as aromatherapy since the changes were favorable, was managed to integrate those users that were difficult to handle but finally there is nothing impossible, as i mentioned earlier i had difficulties, fear, heteroaggression but nothing made me change my mind and i made great changes in the life of each user.

\section{DISCUSSION}

Once the investigation was completed, the changes that users of the Samuel Ramirez Moreno Psychiatric Hospital presented during the application of aromatherapy and Ludotherapy, with which a decrease in anxiety levels was achieved, aggressiveness and behavior so it can be said that aromatherapy and ludotherapy is effective in psychiatric patients.

Dr. Soto (2019) conducted research on aromatherapy used in mental health, describing evidence in favor of aromatherapy, mainly in lavender oil which attributes great benefits in stress, anxiety, depression, sleep disorders, cognitive disorders. So aromatherapy is a great option, simple and low-cost, which can be used as a complement to treatments aimed at restoring mental health and associated disorders. These effects result from the perception of the odor and components of essential oils on specific areas of the brain, lavender oils have beneficial effects on stress, anxiety and depression either by mouth or by inhalation. The most effective oil is lavender oil that is compared as anti-anxiety drugs. The essential oil already mentioned can be a therapeutic resource to consider for the treatment of stress and anxiety, it is economical and safe and more economical than most psychodrugs Dr. Casanova says (Casanova 2019). The author Rosales mentioned in his research that, in the hospital setting, lavender essential oils were found to decrease preoperative stress levels (Rosales,2019). 
So it is important to find answers in natural sources such as strategies, already mentioned in the research, where it was possible to observe the behavioral changes and the coping with stress that psychiatric users presented with alternative medicine as was the use of aromatherapy where the evidence mentions stress and anxiety as one of the main variants that aromatherapy provides benefits in response to stress and anxiety mainly.

Author Vargas mentions different disorders that are mentioned below generalized anxiety disorder, panic disorder, depression, anxiety are associated with a number of physical symptoms such as nervousness, restlessness, impatience, fatigue, irritability, muscle tension, tremor, headache, sleep disturbances, sweating, and tachycardia with many more symptoms focusing mainly on psychiatry, the study mentions that aromatherapy has been able to demonstrate significant reductions in anxiety (Vargas,2010).

When aromatherapy is applied it positively influences the physical appearance by stimulating hormones and metabolism. This is important for a balance in the body. Another aspect that favors the use of aromatherapy is the mood causing their feelings and affections to be positive, since the aroma transforms it to a positive and pleasant situation, this is perceived by the nervous system and it is achieved to improve its stress levels (Palomo, 2010).

Despite the limited amount of clinical evidence, scientific basis indicates that certain essential oils are rapidly absorbed by inhalation, leading to alterations in brain function. In turn, this route is described as the most effective for managing stress and depression (Fernandez, 2018). From the articles reviewed in this study, it is possible to identify that the inhalation of oils is able to stimulate the limbic system generating positive effects on memory that can bring to mind pleasant memories of lived situations. serotonin and other neurotransmitters are released and can act immediately on the individual. The emotional symptoms for which the therapeutic use of essential oils is often used are anxiety, depression and stress, which are occurring at different times in the human life cycle(Fajardo,2018). Specifically mentions 10 types of oils that are more versatile and useful for the family, we will focus on the wash oil that was used during the investigation. Lavender oil is prepared by steam distilation of the flowers of the plant, has a fresh, balsamic and wood odor that can be accompanied by other oils especially citrus and floral. Its main properties are analgesic, anticonvulsant, antidepressant, antiseptic, healing, diuretic, sedative and tonic. Its main use is in depression, headache, insomnia, migraine, nervous tension and stress-related disorders.

So it is important to contemplate aromatherapy in the treatment with users as well as the research that the authors mention in different circumstances but that the results are favorable in any of the different situations.

Another research that was carried out with psychiatric users was the Ludotherapy that had relevance in the lives of people mainly those with different mental disorders, which focuses on quality of life, rehabilitation and integration in the environment around them. Today most psychiatric hospitals have a number of rehabilitation services or programs that aim to improve the health status of psychiatric users primarily to help them maintain 
the best possible standard of functioning and quality of life. At present, professionals develop various models and rehabilitation programs for the occupation of leisure in recreational activities that cause satisfaction and enjoy activities that are freely chosen according to psychiatric users (Larrinaga, 2010).

The experience of psychiatric hospitalization puts his life on hold due to isolation, deterioration of activities, abandonment of his own family. So recreational activities have shown that they help improve the quality of life. In a group of adult men with mental disorders, a series of recreational activities were carried out that they freely chose, and they were observed to significantly increase their vital satisfaction that favored daily life activities and the group integration of users (Gorbeña, 2010).

In the research presented, favorable changes have been demonstrated thanks to the recreational activities carried out to the users, and also the author Maria Marin mentions the didotherapy as an alternative to decrease the aggressiveness of children since it can be channeled in different ways. the game is a direct channel to establish a relationship, a link. Play promotes the development of multiple roles in children's development in cognitive, social, motor and emotional terms. Play therapy helps children seek skills to express their own feelings. Ludotherapy recognizes that play can enhance emotional growth in children and even adults. The game provides pleasure helps break the daily routine which is an opportunity to relieve the stress and stress that life brings (Marin, 2007).

It is evident that the game allows some distancing from the problems of daily life; consistent with the literature in this respect, which identifies in it the contribution of the playful attitude to the adaptation and sense of life to the extent that it can be incorporated into the everyday. The playful attitude, which provides mainly joy, emotions, fun, allows to face difficulties, overcome frustration, facilitates the expression of emotions and conflict resolution especially in older adults (Muñoz, 2016).

The elderly mainly those suffering from mental disorders need specialized care from professionals to contribute to their quality of life, just as the nursing staff is to promote, execute and perform recreational activities such as music, art dance, painting, sport work and integration body and mind (Tapia, 2014). Older adults perform a variety of recreational activities such as physical and recreational activities often, the health benefits that these activities represent, and the relationships that can be established with others, which favor their social life by avoiding isolation (Farias, 2016). Through the proposed activities, the elderly improve their life, thanks to the various activities mentioned, since they acquire greater confidence in their work and as a treatment, since they arouse great interest in the elderly, incorporating an active life promoting a quality life (Goyes, 2015).

\section{Referencias}

Casanova, R,.(2019).Aceites esenciales en el estado de ánimo,Fisioterapia,18(2).101136.Consultado el 1 de Abril del 2021 en http://diposit.ub.edu/dspace/bitstream/2445/159478/1/697665.pdf 
Vol.10, No.1, pp.15-25, 2022

Print ISSN: ISSN 2053-406X

Online ISSN: ISSN 2053-4078

Farías., D, (2016). Ludoterapia en el adulto mayor.educ.1(1).10-130 Consultado el 28 de junio del 2021 en https://isfd86-bue.infd.edu.ar/sitio/-investigacion-enef/upload/LUDOTERAPIA_EN_EL_ADULTO_MAYORpdf

Fajardo, L. (2018). Efectos de los aceites esenciales en los síntomas emocionales de la ansiedad, depresión y estrés, Salud,2(1).15-56. Consultado el 10 de Mayo del 2021 en https://www edu.co/bistraen/hunde/11158/920/Zuluaga\%20Ramirez.pdf; sesionad=451E6FA539B4613E9C897CAB7357C6D

Fernández, E, (2018). Aromaterapia, Medicina,3(2).80-90. Consultado el 26 de junio del 2021 en https://www.medic.org/pdf/09374847/.pdf

Gorbeña, S, (2010) Practica del ocio de las personas con trastornos mentales crónicos, Salud mental1(1).77-113.Consultado el 22 de junio del 2021 en http://www.deusto-.es/ud/openaccess/ocio/pdfs_ocio/ocio14.pdf

Goyes., A. (2015). Actividad física recreativa en el adulto mayor. Educación Física y Deporte, 34 (1), 239-267. Consultado el 20 deJunio2021. http://doi.org/10.17533/udea. efyd.v34n1a

Larrinaga, V,.(2010).El ocio en los Hospitales Psiquiatricos.Salud.2(1).37-69 Consultado el 19 de Junio del 2021 en http://www.publicaciones.es/ud/openaccess/ocio/pdfs_ocio/ocio14.pdf

Marín, M, (2007).Aplicación de la ludoterapia para la reducción de la agresividad en niños.Ludoterapia1(1)56-70.Consultado en 20 de Julio del 2021 en http://pace.uazuay.edu.ec/bitstream/datos/1080/1/06255.pdf

Muñoz, C, (2016) El juego como recurso terapéutico en la intervención comunitaria con personas mayores. Educación y deporte 16(1):84-97. Consultado en 30 de Julio del 2021 en http://scielo.sld.cu/pdf/hmc/v16n1/hmc06116.pdf

Palomo, M., (2010). Aromaterapia. Salud. 2(1).6-29. Consultado el 12 de Mayo del 2021 en http://biblioteca.usac.edu.gt/07/07_1776.pdf

Rosales, L,. (2019). Composición química y efecto de los aceites, Arnaldoa,26(1).381390.Consultado el: 18 de mayo del 2021 en http://www.scielo.org.pe/pdf/arnal/v26n1/a19v261.pdf

Soto, M, (2019). Aromaterapia en la salud mental, Medicina Naturista,1(3).20-26. Consultado el: 21 de Marzo del 2021 en https://www.researchgate.net/publication/330184922_Aromaterapia_en_la_s alud_mental

Sierra, H. (2010). Manual de aromaterapia. nacional1(1).2-26. Consultado el 1 de Junio del 2021 en https://musicalrecursos.files.wordpress.com/2012/11/manualaromaterapia.pdf

Tapia. M, (2014). Impacto de la ludoterapia en el adulto mayor. Salud.2(1).33-90

Consultado el 30 de Junio del 2021 en https://Space.ucuenca.edu.ec/bitstream/123456789/20978/1/Tesis\%20Pregra do.pdf

Vargas, P, (2010). Efectos de la aromaterapia en el servicio Medicina del Hospital, Blacpma,5(4).84-91. Consultado el 14 de febrero del 2021 en https://www.redalyc.org/pdf/856/85650406.pdf 